\title{
Nurses' help in psychiatric out-patient clinics
}

\author{
Philip Meats and Terry Ashton
}

\begin{abstract}
Increasing referrals to psychiatric clinics, combined with restricted medical manpower, require innovative ways of meeting the demands. We appointed a nurse to help in an out-patient clinic. The nurse recorded new patients' case histories and presented them to the consultant, who could then see the patients in less time. In the first 15 months the clinic saw 260 new patients, compared with 190 in the previous period. The median walting time for appointments came down from 32.5 to 22.5 days ( $P=0.018$ ). Patients reported a high level of satisfaction with seeing a nurse and a doctor.
\end{abstract}

A recent report from the National Association of Health Authorities and Trusts (NAHAT, 1996) indicated that among medical specialities psychiatry has the greatest difficulties recruiting into consultant and training grade posts. At the same time, demands on psychiatrists' time continue to increase. For example, referrals for out-patient consultations have risen despite the proliferation of community psychiatric nurses (CPNs) and counselling services. Obtaining funding for new medical posts, even if there were recruits to fill them (see Jolley, 1996) is difficult, so alternative ways of meeting increased demand must be explored.

Nurses are increasingly looking to expand their role. Other specialities have experimented with nurse assistants (Denner, 1995; Dawe, 1996). We decided to appoint an ' $E$ ' grade nurse to assist in a psychiatric out-patient clinic, and to evaluate the effects on the time taken by the consultant, acceptability to patients and the effect on the waiting list.

\section{The study}

Clinical supervision for the nurse was arranged to be entirely a medical responsibility. Physical medical problems and treatment issues require the presence of the doctor. The locus of clinical responsibility was defined explicitly as remaining with the consultant.

The nurse was initially given tutorials and written instruction in systematic history-taking, including the Institute of Psychiatry's Notes on Eliciting and Recording Clinical Information
(Department of Psychiatry Teaching Committee, Institute of Psychiatry, 1973). Then the nurse sat in on the consultant's clinics. The next step was to see and present follow-up patients to the consultant, who then saw the patients himself.

When the consultant was satisfied that the nurse was able to elicit and present the history in an acceptable manner, appointments were arranged for the nurse to see new patients to take a routine psychiatric history. The nurse then presented the case to the consultant before the consultant saw the patient. The consultant made his assessment and decided on the plan of management. Follow-up appointments were made with the nurse in suitable cases, supervised in the same way. The nurse wrote the draft clinic letters for the consultant to check.

The times taken by the nurse and the consultant at each stage were recorded for all nurse appointments. The total time taken by the consultant was compared against a 'standard' allocation of 60 minutes per new patient, 40 minutes for re-referrals and 20 minutes for follow-ups when seeing the consultant only. Separate comparisons were made for the initial three months and the subsequent 12 months.

Patient satisfaction was assessed by sending a questionnaire by post to all patients who attended in the first six months. Five items were closed questions, with a final open question about what the patient felt could have been improved.

Waiting times were calculated from the date of receipt of the referral to the date of the appointment. The first 15 months with the nurse assistant were compared with the previous 15 months for the same consultant.

\section{Findings}

The nurse saw 91 new referrals, 24 re-referrals and 218 follow-ups in the first 15 months. The times taken by the consultant are shown in Table 1. Results for the first three months are compared with the subsequent 12-month period. Already in the initial period the time taken by the 
Table 1. Time taken by consultant with clinic assistant

\begin{tabular}{|c|c|c|c|c|c|}
\hline \multirow{2}{*}{\multicolumn{2}{|c|}{$\begin{array}{l}\text { Allocated consultant time without assistant } \\
\text { (min) }\end{array}$}} & \multicolumn{2}{|c|}{ First 3 months } & \multicolumn{2}{|c|}{ Next 12 months } \\
\hline & & $\begin{array}{l}n \\
14\end{array}$ & $\begin{array}{l}\text { Mean time for consultant } \\
(\mathrm{min})\end{array}$ & $\begin{array}{l}n \\
77\end{array}$ & $\begin{array}{l}\begin{array}{l}\text { Mean time for consultant } \\
(\mathrm{min})\end{array} \\
24.7\end{array}$ \\
\hline $\begin{array}{l}\text { New patient } \\
\text { Re-referral } \\
\text { Follow-up }\end{array}$ & $\begin{array}{l}60 \\
40 \\
20\end{array}$ & $\begin{array}{r}14 \\
4 \\
18\end{array}$ & $\begin{array}{l}27.3 \\
32.5 \\
13.0\end{array}$ & $\begin{array}{r}77 \\
20 \\
200\end{array}$ & $\begin{array}{r}24.7 \\
17.0 \\
5.2\end{array}$ \\
\hline
\end{tabular}

consultant to supervise cases was reduced compared with the usual time allocated for clinic patients. As expected, the consultant time was reduced even further in the next 12 months as the nurse became more experienced.

The first 46 new patients were sent a postal questionnaire, and 23 replied (50\%). All respondents indicated satisfaction with the arrangement of seeing the nurse first and then the consultant. Two asked for more time with the consultant. One patient who was already being seen by a CPN suggested that the CPN should have presented the case rather than the clinic nurse. No adverse comments have been received from referrers (who were not directly canvassed).

The numbers of new and re-referred patients were counted, and waiting times calculated. The total number of such patients was 190 in the 15 months before the nurse started. This increased to 260 in the 15 months after starting. of whom the nurse saw 115. The median waiting times decreased from 32.5 days in the 15 months before the nurse started, to 22.5 days in the next 15 months (MannWhitney $U$ test, $P=0.018$ ).

\section{Comment}

The assistance of a nurse in a general psychiatric out-patient clinic markedly reduced the time taken by the consultant to see a given number of patients. This was particularly evident for new patients, and still true for rereferrals and follow-up visits. The waiting time for new appointments reduced considerably despite an increased number of referrals. The arrangement of seeing a nurse first, followed by the consultant appeared highly acceptable to patients.

There may be some degree of incompleteness in assessing the amount of the consultant's time, particularly in the induction period. For example, having the nurse sit in on a clinic would have taken extra time because of having to make introductions to patients, as well as time taken in 'teaching' discussions once the patient left. If anything, this would exaggerate the effect of the comparison of the initial three months with the subsequent twelve months. Also the consultant was involved in initial planning and negotiations, in drawing up the job description, in negotiating with administrative staff about clinic procedures and in finding a room for the nurse to use to see patients. The time taken for these activities was not recorded. However, now that the service is established and running smoothly, the amount of such administrative time is virtually nil. Underestimation of saving in consultant time would also arise if the nurse saw patients more often as follow-ups than the consultant would have done. The subjective impression was that the nurse did offer more counselling visits, but it was outside the scope of this study to address this question.

We might be criticised for instituting a conveyor belt' type of clinic with little therapeutic input. This is not the case. New patients had a full hour of face-to-face contact with the nurse. and also considerable time with the consultant. It was beyond the scope of the study to assess outcomes directly, but the authors' impression was that the quality of clinic visits was maintained and that patients appreciated the contact with the nurse.

There are several advantages in having a nurse assist in psychiatric out-patient clinics. The patient has a systematic and thorough assessment and still gets to see the consultant, but the consultant can see more patients because of the shorter time taken with each one. There are also gains for the nurse, including increased job satisfaction, development of assessment and counselling skills and an increase in confidence and autonomy.

There were potential disadvantages but these were minimal. Because of the necessity for medical supervision at all times there was a need for extra effort in arranging annual leave periods. There was occasional confusion among patients and referrers, thinking that the clinic assistant was a doctor. This situation also arises elsewhere, particularly with male CPNs and where nurses are not in an identifiable nursing uniform.

The overall conclusion is that a nurse can help in a psychiatric out-patient clinic. Although this is only a single observation, which needs 
replicating, nevertheless it does offer another way of responding to the ever increasing demands for psychiatric consultations.

\section{References}

DAwE, V. (1996) Theatre nurse opens up an age-old wound Hospital Doctor, 18 July, 34.

DENNER, S. (1995) Extending professional practice: benefits and pitfalls. Nursing Times, 91, 27-29.

DEPARTMENT OF PSYCHIATRY TEACHING COMMITTEE. INSTTTUTE OF PsYchIATRY (1973) Notes on Eliciting and Recording Clinical Information. London: Oxford University Press.
JOLLEY, D. (1996) Light into the darkness: bringing old age psychiatry to unfashionable places. Psychiatric Bulletin. 20. 174-176.

National Association of Health authormes and Trusts (1996) Hospital and Community Health Services Medical Recruitment Survey. London: NAHAT.

*Philip Meats, Consultant Psychiatrist, and Terry Ashton, Clinic Nurse Assistant, Millbrook Unit, Kings Mill, Nottinghamshire NG17 4JT

*Correspondence

\section{Seminars in Clinical Psychopharmacology Edited by David J. King}

Psychopharmacology is a key both to the understanding of the biological basis of severe mental illness and to the rational use of drugs in clinical psychiatry. This book is an excellent introduction to an ever-expanding and fascinating subject, linking relevant basic neuropharmacology to clinical practice. It aims to bridge the gap between the theoretical basis for the mode of action of psychotropic drugs and guidance on their clinical use, and should increase interest in and understanding of the drugs widely used in clinical practice. $£ 20.00,544 p p ., 1995$, ISBN 0902241737

Available from bookshops and from the Publications Department, Royal College of Psychiatrists, 17 Belgrave Square, London SW1X 8PG (Tel. 01712352351 extension 146) 